Diabetologia 10, 709-715 (1974)

(C) by Springer-Verlag 1974

\title{
Effect of a Low Dose of Alloxan on Blood Glucose, Islet Beta Cell Granulation, Body Weight, and Insulin Resistance of ob/ob mice
}

\author{
J. Solomon*, R.J. Bulkley, and J. Mayer \\ Department of Nutrition, Harvard University School of Public Health, Boston, Massachusetts, USA
}

Received: March 7, 1974, and in revised form: June 28, 1974

Summary. The effects of a low dose of alloxan on the blood glucose, islet beta cell granulation, body weight, insulin resistance, glucose tolerance, and responses to fasting and growth hormone were studied in $o b / o b$ mice, which respond to a single low dose of alloxan with a rapid $(24 \mathrm{~h})$ and long-term (108 day) significant decrease in blood glucose levels, and increase in islet beta cell granulation. Three weeks after alloxan administration, insulin resistance is ameliorated in alloxan-treated obese mice whose body weight is not significantly different from their obese controls. A low dose of alloxan has a therapeutio influence on glucose management in $0 b / 0 b$ mice: reduced glycemia, improved glucose tolerance, and increased tolerance to fasting. Growth hormone induces a similar hyperglycemic response in alloxan-treated and control mice.

Key words: ob/ob mice, alloxan islet granulation, glucose management, insulin resistance and body weight, growth hormone.
In a preliminary report [24] it was shown that administration of a single low dose of alloxan to fivemonth old C56BL/6J ob/ob mice caused an immediate $(20 \mathrm{~h})$ and long-lasting (56 day) increase in pancreatic beta cell granulation, which was accompanied by a concomitant decrease in glycemia and glycosuria.

The pancreatic islets of $o b / o b$ mice are markedly vascular, and hypertrophied [8]; the beta cells are generally degranulated, and the nucleii, nucleoli [10] and Golgi bodies [11] enlarged. The $o b / o b$ mouse shows a number of metabolic abnormalities $[1,3,4,5,14,17$, 25], including insensitivity to high doses of insulin [2, 23 ], and a rapid response to the hyperglycemic action of growth hormone [18, 22].

In this study the long-term (176 day) effect of a single low dose of alloxan on the body weight, blood glucose levels, islet beta cell granulation, insulin resistance, glucose tolerance and response to growth hormone was examined in the obese hyperglycemic mouse.

\section{Materials and Methods}

C57BL/6J ob/ob mice and their lean controls were obtained from the Jackson Memorial Laboratories, and maintained on Purina Laboratory Chow ad lib. Three days before alloxan administration, body weight and blood sugar level determinations were performed on 49 obese and 17 lean 5 month old female mice. The animals were then randomized as follows: 18 obese and 7 lean mice served as untreated controls; 15 obese and 10 lean

* Supported in part by grants in aid from the National Institutes of Arthritis and Metabolic Diseases (A-2911) National Institutes of Health, U.S. Public Health Service, Bethesda, Maryland; and The Fund for Research and Teaching of the Department of Nutrition, Harvard, School of Public Health, Boston, Massachusetts. mice were treated with alloxan. All animals were fasted for $48 \mathrm{~h}$, after which the appropriate obese and lean mice were treated with a single intraperitoneal injection of alloxan and immediately returned to ad lib. feeding. Alloxan dosage was the same as that used in an earlier study [24]: lean mice received $170 \mathrm{mg} / \mathrm{kg}$ body weight; obese mice received $85 \mathrm{mg} / \mathrm{kg}$. Body weights and blood sugar levels were measured at various intervals from the day of alloxan administration to 176 days post-alloxan. The Somogyi-Nelson [19] micromethod was used to determine blood glucose from duplicate samples. Some animals from each group were chosen at random and sacrificed at various times from day one to day 176 after alloxan and the pancreata were removed at necropsy for histological examination. Pancreata were placed in Bouin's solution and stained with Gomori's aldehyde fuchsin [7] after oxidation with acidified permanganate, and counterstained with Halmi's [9] method.

\section{Fasting and Insulin}

Fifteen days after the single dose of alloxan, the obese mice were fasted for $24 \mathrm{~h}$ (water was accessible), and fasting body weights and blood glucose levels were determined. Twenty-two days after alloxan administration food was withdrawn from the obese mice two hours before they were injected subcutaneously with 20 units NPH insulin per kilogram body weight; blood samples were obtained two hours after insulin administration. The mice were then returned to feeding. Lean mice were fasted overnight on the eleventh postalloxan day to determine fasting blood glucose levels. On the fifteenth post-alloxan day food was removed from lean mice for two hours before they were injected subeutaneously with 10 units NPH insulin per kilogram; blood samples were taken two hours later, and the mice re-fed, 


\section{Glucose Tolerance Tests}

At fifty-seven days post-alloxan (for the obese), and 45 days (for the lean), the mice were fasted overnight. Blood samples were obtained from the fasting mice, and then one, two and four hours after intraperitoneal administration of glucose. The lean mice received $20 \mathrm{mg}$ glucose; the obese received $50 \mathrm{mg}$ glucose. Food was withheld during this period.

At 120 days post-alloxan, a second glucose tolerance test was run on the same obese mice; after an overnight fast, blood glucose samples were taken from fasting mice and then 15,30 and 60 min after intraperitoneal administration of $50 \mathrm{mg}$ of glucose.

\section{Growth Hormone}

In an effort to determine the effect of growth hormone on the blood glucose of alloxanized obese mice, a new group of fourteen 4 month old female C57BL/6J ob/ob mice was obtained from Jackson Memorial Laboratories and maintained on Purina Laboratory Chow ad $l i b$. Body weights and blood glucose levels were determined 13 and 3 days before ceived $2 \mathrm{mg}$ beef growth hormone subcutaneously. Twelve hours later, blood glucose levels were determined and the animals were sacrificed. The four remaining mice from each group received $1 \mathrm{mg}$ growth hormone per day for 3 days, from day 7 to day 9 postalloxan. On the tenth day, blood glucose levels were determined and the animals sacrificed.

\section{Results}

\section{Body Weight and Blood Glucose Levels in Long-Term Alloxanized Animals}

The blood sugar levels and body weights of alloxantreated obese mice and their controls are shown in Fig. 1. Twenty four hours after alloxan, the blood glucose levels of obese mice were lower than those of the non-treated obese controls. Forty eight hours postalloxan, the blood sugar of the control (non-alloxanized) obese mice was back to its high level whereas that of the alloxanized obese mice was significantly $(p=$ $<0.01)$ lower.

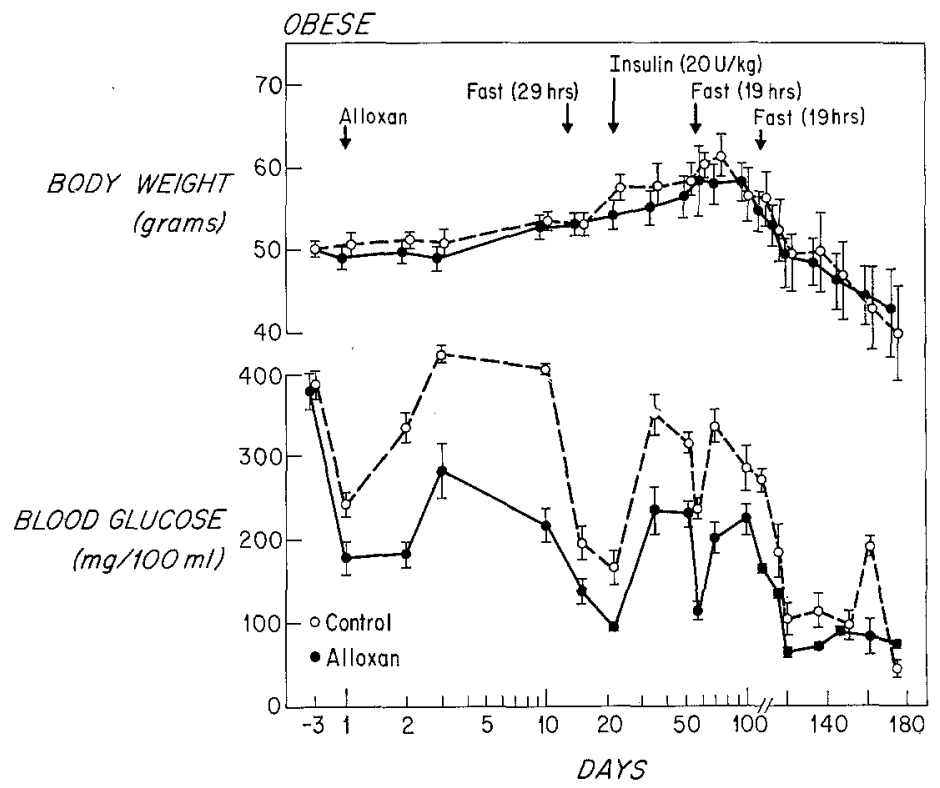

Fig. 1. Mean body weights and blood glucose values of alloxan-treated and control obese mice observed 3 days before and periodically (on days $1,2,3,10,15,22,35,52,57,71,101,108,116,120,136,148,162,176$ ) after alloxan administration. Each point represents a mean obtained from 10 to 18 alloxan-treated and 7 or 8 control mice, and the vertical bars show the standard error of the mean

alloxan administration. With these base lines established, all mice were fasted for $48 \mathrm{~h}$, and randomized into two groups: 7 obese mice were treated with a single intraperitoneal injection of alloxan $(85 \mathrm{mg} / \mathrm{kg}$ body weight); the remaining 7 obese mice served as nonalloxanized controls. Both groups were immediately returned to ad lib. feeding. Blood glucose levels and body weights were determined for both groups on the second, fourth, and seventh post-alloxan day.

On the seventh day, 3 mice from each group re-
The blood glucose values of alloxan-treated obese mice remained significantly $(p=<0.01, p=<0.05)$ lower than obese controls for a period of 108 days postalloxan. About 108 days after alloxan administration, the blood glucose levels of both the alloxan-treated and control mice began to decline (Fig. 1). From 116 to 162 days after alloxan administration, the blood sugar values of alloxan-treated obese mice remained consistently, but not significantly, lower than control values, until the 176 th day post-alloxan, when the 
blood glucose levels of alloxan-treated mice were higher than controls. Body weight of alloxan-treated obese mice was similar to control values throughout the experimental period.

Alloxan-treated lean mice (Fig. 2) showed the expected blood glucose response to alloxan administration. There was an initial hypoglycemia $20 \mathrm{~h}$ postalloxan; glucosuria and hyperglycemia occurred $48 \mathrm{~h}$ after alloxan, and persisted throughout the 176 day experimental period. Over this same period, the control lean mice showed normal blood sugar values and gained $4.3 \mathrm{~g}$, while the alloxan-treated lean mice gained $0.6 \mathrm{~g}$.

\section{Insulin Administration and Fasting}

In obese mice, the percentage decrease in blood glucose following a large dose $(20$ units $/ \mathrm{kg}$ ) of insulin was greater in alloxan-treated than in non-alloxanized obese mice (Fig. 1); the blood glucose values of alloxanized mice fell from a fasting level of 137 to $94 \mathrm{mg}$ per $100 \mathrm{ml}$ (a 31 percent decrease); that of non-alloxanized, obese females was depressed from a fasting level of 195 to $165 \mathrm{mg}$ per $100 \mathrm{ml}$ (a $15 \%$ decrease). After in- mice showed a $60 \%$ decrease, lean controls a $37 \%$ decrease, after a nineteen hour fast (Fig. 2).

\section{Glucose Tolerance Tests}

The responses of the same obese mice at 7 months of age ( 57 days post-alloxan) and 9 months of age (120 days post-alloxan) to glucose tolerance tests are shown in Fig. 3. When blood samples were taken from fasting mice and then 1, 2 and $4 \mathrm{~h}$ after a glucose load (57 days post-alloxan), the blood sugar responses of both the alloxan-treated and control obese mice were obtunded. When blood samples of the same mice were taken from fasting animals and then 15,30 and $60 \mathrm{~min}$ after glucose infusion (120 days post-alloxan) there was a sharp rise at $15 \mathrm{~min}$ and a slight depression in blood sugar levels at $30 \mathrm{~min}$ of both the alloxanized and control obese mice. However, by $60 \mathrm{~min}$ the blood glucose levels of alloxanized mice were sharply depressed, whereas the blood glucose levels of non-alloxanized obese mice remained high. The glucose tolerance curves obtained 45 days after alloxan administration from alloxan-treated and_control lean mice, one, two and

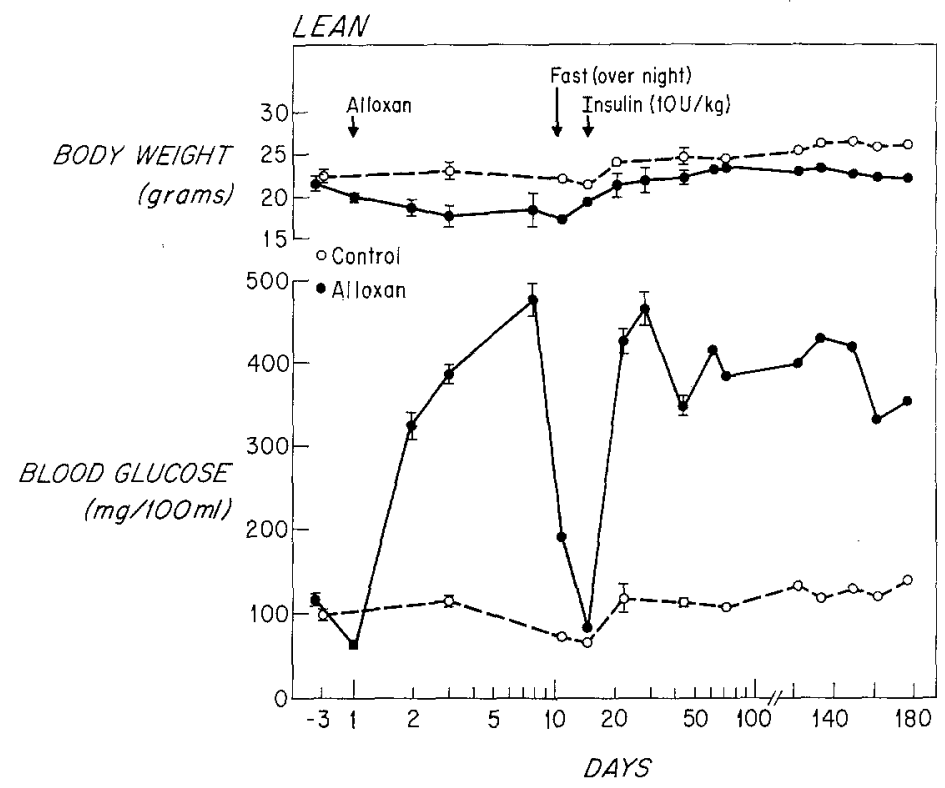

Fig. 2. Mean body weights and blood glucose values of alloxan-treated and control lean mice observed 3 days before and periodically (on days $1,2,3,8,11,15,22,28,45,63,71,122,134,150,162$ and 176) after alloxan administration. Each point represents a mean obtained from 6 to 10 alloxan-treated and 6 or 7 control mice, and the vertical bars show the standard error of the mean

sulin administration (Fig. 2), the blood glucose of alloxanized lean mice fell from a fasting level of 192 to $83 \mathrm{mg}$ per $100 \mathrm{ml}$ (a $57 \%$ decrease); lean controls showed an $11 \%$ decrease (from 73 to $65 \mathrm{mg}$ per $100 \mathrm{ml}$ ).

After a twenty-nine hour fast, there was a $37 \%$ decrease (from a pre-fast value of 217 to $137 \mathrm{mg}$ per $100 \mathrm{ml}$ ) in blood glucose values of alloxan-treated obese mice; non-alloxanized obese mice showed a greater $(52 \%)$ fall in blood sugar levels, from a pre-fast level of 406 to $195 \mathrm{mg}$ per $100 \mathrm{mI}$, (Fig. 1). Alloxanized lean four hours after $20 \mathrm{mg}$ glucose were typical of diabetic and normal responses.

\section{Growth Hormone}

Growth hormone elicits a similar hyperglycemic response in alloxan-treated as in non-alloxanized, control obese mice (Fig. 4). Twelve hours after administration of $2 \mathrm{mg}$ growth hormone, the blood glucose levels of alloxan-treated mice were increased $33 \%$. Blood sugar values of control mice increased $29 \%$. After 3 days 
of growth hormone administration (1 $\mathrm{mg}$ per day), blood glucose levels of alloxan-treated obese mice were increased $41 \%$; blood sugar values of control obese mice increased $48 \%$.

\section{Alloxan and Islet Histology}

The hypertrophied, relatively degranulated islet tissue of an untreated obese mouse is shown in Fig. 5. Twelve days after alloxan, the beta cells of obese mice were well granulated (Fig. 6) and appeared healthy.
The beta cells of an obese mouse are seen to be relatively well granulated 60 days after treatment with alloxan (Fig. 7). The beta cells of a lean mouse twenty four hours after alloxan are so heavily granulated that cellular outlines are difficult to define. Forty eight hours after alloxan in the lean mouse, evidence of beta cell destruction is clear, and by $72 \mathrm{~h}$ the beta cells were either degranulated or contained dense granules and pyknotic nuclei.

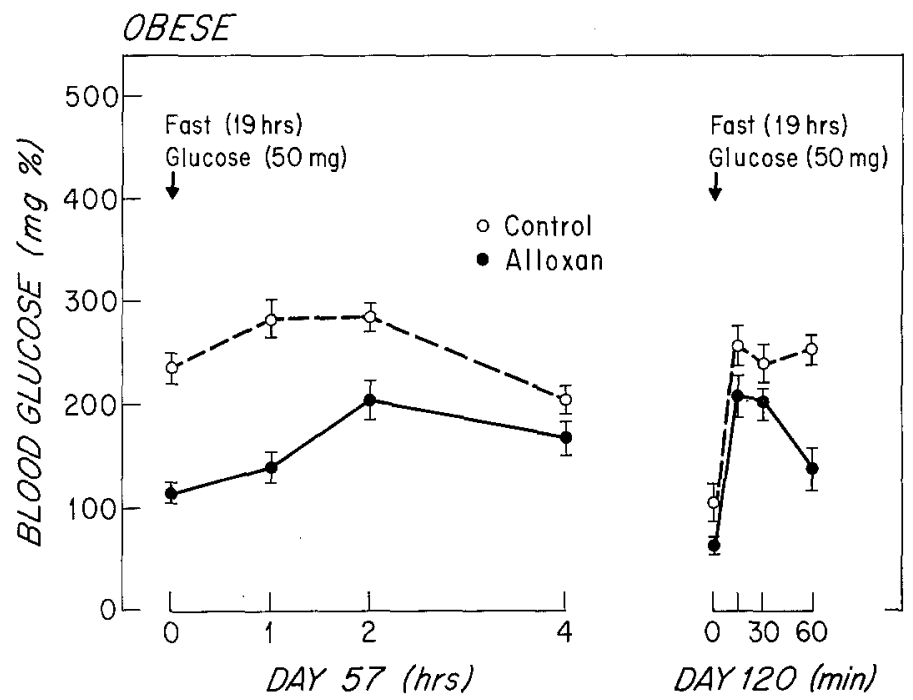

Fig. 3. Mean glucose values obtained from glucose tolerance tests performed on the same obese mice at 7 months of age (57 days post-alloxan) and 9 months of age (120 days post-alloxan). All mice were fasted for 19 hrs prior to intraperitoneal administration of $50 \mathrm{mg}$ glucose. Blood samples were obtained from fasting mice and then 1, 2 and 4 hrs (57 days) and 15, 30 and $60 \mathrm{~min}$ (120 days) after glucose administration. Each point represents the mean of 6 mice and the vertical bars show the standard error of the mean

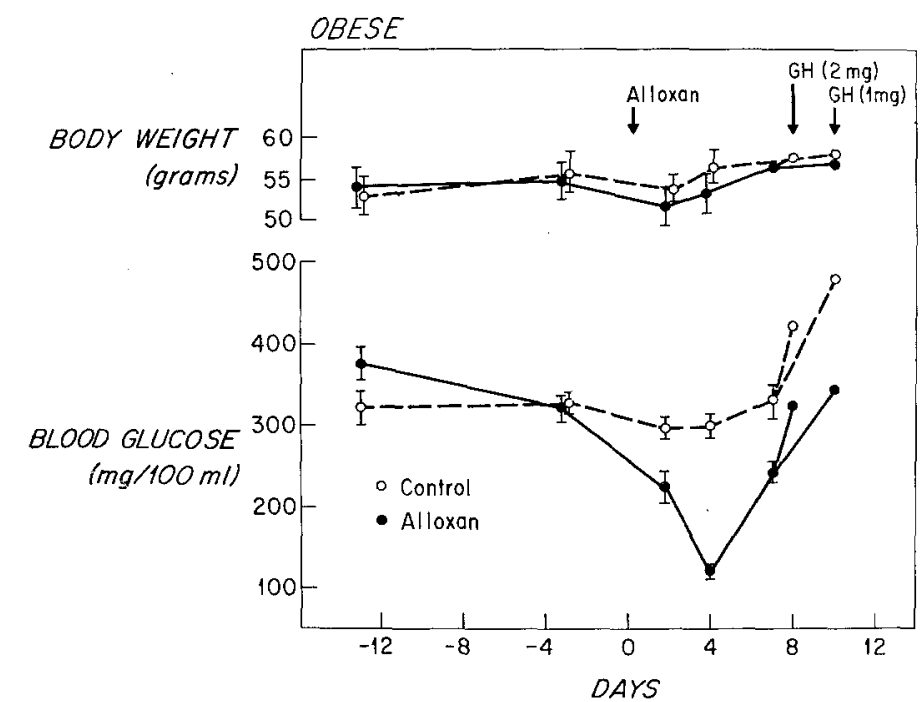

Fig. 4. Mean body weight and blood glucose values of alloxan-treated and control obese mice observed 13 days before and periodically for 12 days after alloxan and growth hormone administration. On the 7th post-alloxan day, 3 mice from each group (alloxan-treated and control) received $2 \mathrm{mg}$ growth hormone, and were sacrificed 12 hrs later. Four mice from each group received $1 \mathrm{mg}$ growth hormone per day from' day 7 to day 9, and were sacrificed on day 10 . Each point represents the mean of 7 mice (up to day 7 post-alloxan); values obtained after growth hormone administration represent means obtained from 3 ( $2 \mathrm{mg} G H)$ or $4(1 \mathrm{mg} G H)$ mice. Vertical bars show the standard error of the mean 


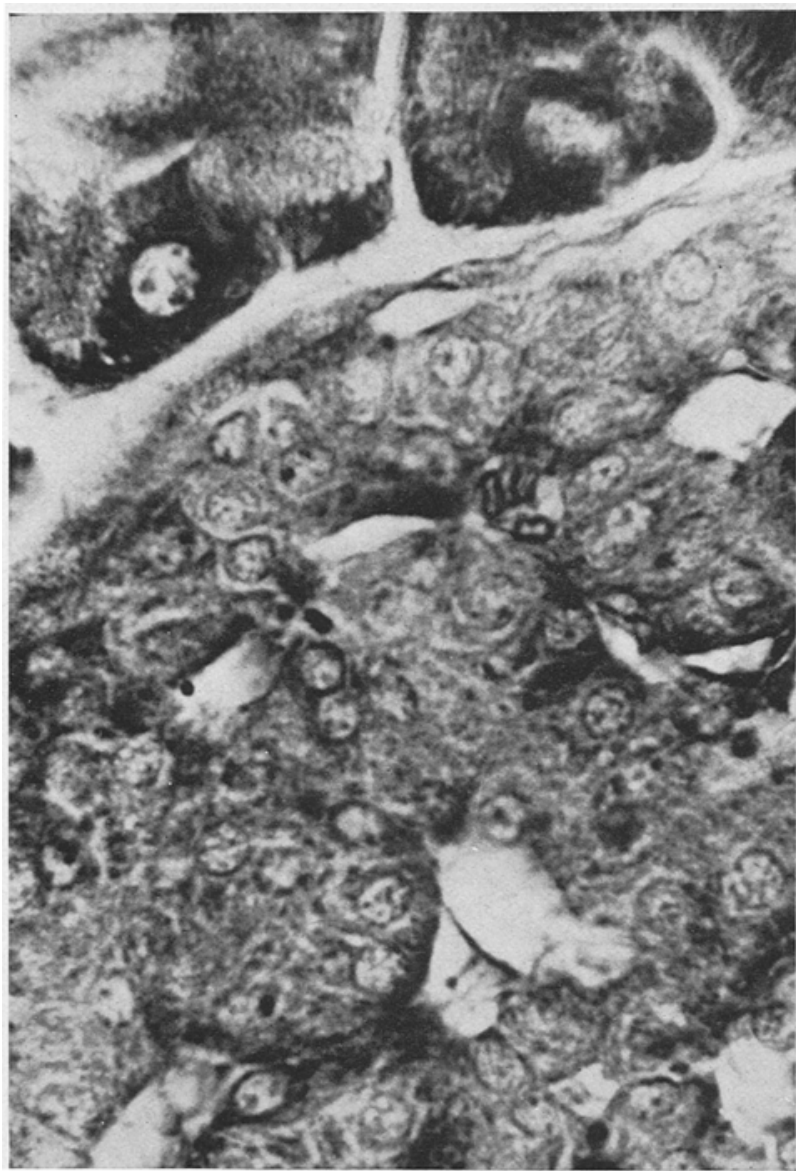

Fig. 5. Portion of the pancreatic islet of an untreated ob/ob mouse. Note degranulation of beta cells. Gomori's Aldehyde fuchsin. $\times 950$

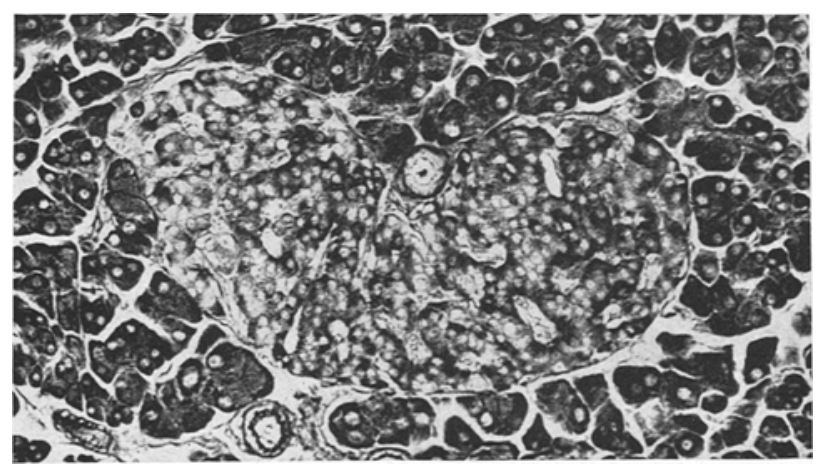

Fig. 7. Pancreatic islet of an $o b / o b$ mouse 60 days after treatment with alloxan. Note granulation of beta cells. Gomori's Aldehyde fuchsin. $\times 200$

\section{Discussion}

The concept that insulin sensitivity is related to body weight has recently gained attention [1]. Mahler and Szabo[16] found that several days after alloxan administration, insulin resistance was ameliorated in $o b / o b$ mice without a decrease in body weight. We find

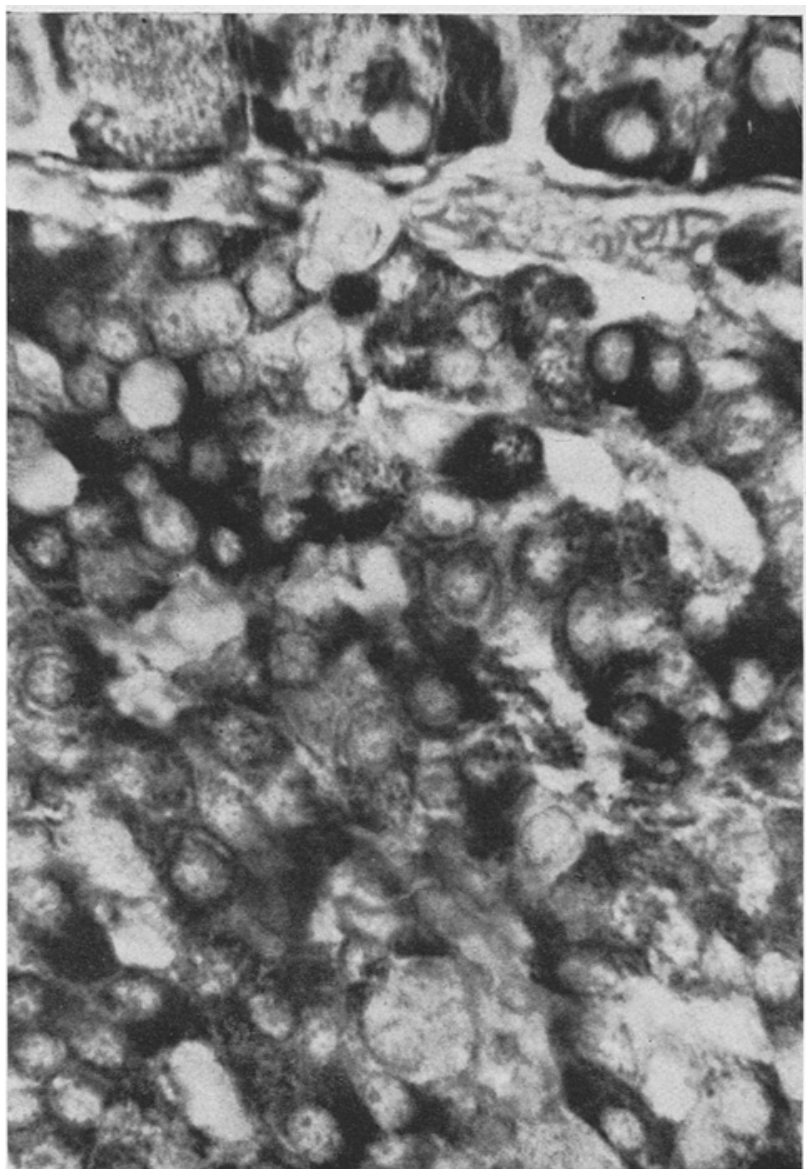

Fig. 6. Portion of the pancreatic islet of an $o b / o b$ mouse 12 days after treatment with alloxan. Note granulation of beta cells. Gomori's Aldehyde fuchsin. $\times 950$

that twenty-two days after alloxan administration, when sufficient time is allowed for physiological adjustment to experimental conditions, insulin resistance is ameliorated in alloxan-treated obese mice whose body weight $(54.2 \pm 1.6 \mathrm{~g})$ is not significantly different from that of their obese controls $(56.5 \pm 1.9 \mathrm{~g})$.

Herberg et al. [12] reported that in non-fasting ob/ob mice the peak of blood glucose values during glucose tolerance tests appeared twenty minutes after glucose injection, and that the subsequent slope was similar in most groups, but delayed in mice older than 7 months.

In the present experiment, when the blood sugar responses of fasting 7 month old alloxanized and control obese mice are examined 1,2 and $4 \mathrm{~h}$ after a glucose load, both the alloxan-treated and control mice appear to have an obtunded response. However, closer inspection, at 15, 30 and $60 \mathrm{~min}$, of the glucose tolerance tests of fasting, 9 month old, alloxanized and control obese mice shows that by $60 \mathrm{~min}$ the blood glucose levels of alloxanized mice is sharply depressed, whereas control levels remain high. This suggests that alloxanized mice have a more appropriate response to 
a glucose challenge than do their obese controls. In addition, the increased ability of alloxan-treated obese mice to tolerate a fast indicates that a low dose of alloxan may have a therapeutic effect on glucose management in the obese mouse.

The hyperglycemic response of $o b / o b$ mice to growth hormone is well documented $[18,22]$. Our results on the effect of growth hormone in alloxanized obese mice indicate that growth hormone elicits a similar hyperglycemic response in alloxan-treated and control oblob mice.

The effect of alloxan on islet cell granulation in $o b /$ $o b$ mice should be considered from the point of view of age, body weight, glucose tolerance, serum insulin and blood glucose levels, since Herberg et al. have shown [12] that in the $o b / o b$ mouse beta cell granulation and glucose management vary with age. Our data indicate that a low dose of alloxan $(85 \mathrm{mg} / \mathrm{kg}$ ), when injected during the transitional phase, tends to permit the beta cells of the female $o b / o b$ mouse to become, and remain, relatively well granulated. In this study, increased granulation of the islet beta cell is accompanied by a decrease in glycemia. Association of increased beta cell granulation with reduction in blood glucose levels is not unique to the $o b / o b$ mouse. Coleman et al. [6] report that regranulation of the islet beta cells is associated with the maintenance of lower blood glucose levels in $d b / d b$ mice.

The effect of alloxan appears to be dose related in $o b / o b$ mice. The response to low doses of alloxan $(85 \mathrm{mg} / \mathrm{kg}$ ) may be similar to the initial, transient (and perhaps stimulatory) phase of alloxan action $[13,15$, $21,26]$; in the obese mouse a low dose of alloxan appears to elicit an arrest at the hypergranulation phase, with its accompanied decrease in glycemia and glucosuria. At this dose insulin resistance is ameliorated. When alloxan is given at $100 \mathrm{mg} / \mathrm{kg}$ [16], the beta cells are reduced in size and contain fewer granules, but blood glucose is not increased and insulin resistance continues to be ameliorated. At $150 \mathrm{mg} / \mathrm{kg}[20]$ the beta cells are largely destroyed and blood sugar levels are strongly elevated.

A low dose of alloxan appears to have a long term therapeutic effect on glucose management in 5 month old of female C57BL/6J ob/ob mice. After alloxan, the pancreatic beta cells are relatively more granular and glycemia remains reduced for over 3 months. The responses to fasting and glucose tolerance tests are more appropriate in alloxan-treated mice than in their obese controls. While alloxanized mice continue to gain weight at the same rate as controls, insulin resistance is ameliorated, and the hyperglycemic response to growth hormone is unchanged.

\section{References}

1. Bray, G.A., York, D.A.: Genetically transmitted obesity in rodents. Physiol. Rev. 51, 598-645 (1971)
2. Chlouverakis, C., Dade, E.F., Batt, R.A.L.: Glucose tolerance and time sequence of adiposity, hyperinsulinemia and hyperglycemia in obese-hyperglycemic mice (ob/ob). Metabolism 19, 687-693 (1970)

3. Christophe, J., Dagenais, Y., Mayer, J.: Increased circulating insulin-like activity in obese-hyperglycemic mice. Nature 184, 61-62 (1959)

4. Christophe, J., Jeanrenaud, B., Mayer, J., Renold, A.E.: Metabolism in vitro of adipose tissue in obesehyperglycemic and gold thioglucose-treated mice. I. Metabolism of glucose. J. Biol. Chem. 236, 642-647 (1961)

5. Christophe, J., Jeanrenaud, B., Mayer, J., Renold, A. E.: Metabolism in vitro of adipose tissue in obesehyperglycemic and gold thioglucose-treated mice. II. Metabolism of pyruvate and acetate. J. Biol. Chem. 236, 648-652 (1961)

6. Coleman, D. L., Hummel, R.P.: The effects of hypothalamic lesions in genetically diabetic mice. Diabeto. logia 6, 263-267 (1970)

7. Gomori, G.: Aldehyde-fuchsin: a new stain for elastic tissue. Amer. J. clin. Path. 20, 655-666 (1950)

8. Gepts, W., Christophe, J., Mayer, J.: Pancreatic islets in mice with the obese-hyperglycemic syndrome. Diabetes 9, 63-69 (1960)

9. Halmi, N.S.: Differentiation of two types of basophils in the adenohypophysis of the rat and mouse. Stain Technol. 27, 61-64 (1952)

10. Hellman, B., Peterson, B.: The activity of the islet $B$-cells as indicated by the nuclear and nucleolar size in the American obese-hyperglycemic mice. Acta path. microbiol. scand. 50, $291-296(1960)$

11. Hellman, B., Hellerström, C., Larsson, S., Brolin, S. Histochemical observations on the pancreatic islets in normal and obese-hyperglycemic mice. $Z$. Zellforsch. $\mathbf{5 5}, 235-246(\mathbf{1 9 6 1})$

12. Herberg, L., Major, E., Hennings, U., Gruneklee, D., Freytag, G., Gries, F.A.: Differences in the development of the obese-hyperglycemic syndrome in ob/ob and NZO mice. Diabetologia 6, 292-299 (1970)

13. House, E.L., Nace, P.F., Tassoni, J.P.: Alloxan diabetes in the hamster: organ changes during the first day. Endocrinology 59, 433 - 443 (1946)

14. Leboeuf, B., Lochaya, S., Leboeuf, N., Wood, F., Jr., Mayer, J., Cahill, G.E., Jr.: GIucose metabolism and mobilization of fatty acids by adipose tissue from obese mice. Amer. J. Physiol. 201, 19-22 (1961)

15. Lukens, F.D.: Alloxan diabetes. Physiol. Reviews 28, $304-330(1948)$

16. Mahler, R.J., Szabo, O.: Amelioration of insulin sensitivity in obese mice. Amer. J. Physiol. 221, 980$983(1971)$

17. Mayer, J., Jones, A.K. : Hypercholesterolemia in the hereditary obese-hyperglycemic syndrome of mice. Amer. J. Physiol. 175, 339-342 (1953)

18. Mayer, J., Silides, D.J. : A quantitative method of the determination of the diabetogenic activity of growth hormone preparation. Endocrinology 52, 54-56 (1953)

19. Nelson, N.: A photometric adaptation of the Somogyi method for the determination of glucose. J. Biol. Chem. 153, 375-380 (1944)

20. Nordenström, A., Peterson, B., Westman-Naeser, S., Hellerström, C.: Induction of alloxan diabetes in obese-hyperglycemic mice (Genotype ob/ob). Experientia 29, 1142-1143 (1973)

21. Shipley, E.G., Beyer, K.H.: The effect of vagotomy 
and of thoracic sympathectomy on the blood glucose changes in dogs given alloxan. Endocrinology 40, $154-164(1947)$

22. Shull, K., Mayer, J.: Analysis of blood sugar response of obese-hyperglycemic mice and normal mice to hormones: growth hormone, cortisone and cortico. tropin. Endocrinology 58, 1-7 (1956)

23. Shull, K., Mayer, J.: Analysis of blood sugar response of obese hyperglycemic mice and normal mice to hormones: insulin, glucagon and epinephrine. Endocrinology 58, 220-225 (1956)

24. Solomon, J., Mayer, J.: Effect of alloxan on obese hyperglycemic mice. Nature 193, 135-137 (1962)

25. Stauffacher, W., Orci, L., Cameron, D. P., Burr, I.M., Renold, A.E.: Spontaneous hyperglycemia and/or obesity in laboratory rodents: An example of the possible usefulness of animal disease models with both genetic and environmental components. Rec. Progr. Horm. Res. 27, 41-95 (1971)

26. Williamson, J.R., Lacy, P.E.: Electron microscopy of islet cells in alloxan-treated rabbits. AMA Arch. Path. 67, 102-109 (1959)

Dr. J. Solomon

Associate Professor of Biology Boston College

Chestnut Hill

Boston, Massachusetts 02167

USA 